\title{
E-Science and Web 2.0 in Higher Education
}

\author{
Antonija Marinclin, Ivana Mikić, Marija Blažičević \\ Polytechnic in Pozega, Croatia
}

\section{Abstract}

There are many definitions of Web 2.0 which, however, do not exclude each other. Tim O'Reilly and Dale Dougherty first used the term in 2004 when they came up with an idea of conference about Web technology development. Today, we have different numbers of Web 2.0 tools on the Internet with different purpose, and many of them are implemented in education. The education system is subject to a number of changes to ensure the quality of the studies. Thus, the introduction of new technology that allows better communication, research and access to lectures alone creates a better learning environment and easier to study. The presence of new technologies provides an entirely new approach to the education system. In this paper we will present a few Web 2.0 tools and also how they affect in Croatian education on polytechnics. By polling of the students we want to determine how much they are familiar with web technologies in a way to examine their current habits and how they should be altered to accept new technologies in education and educational systems. With results of the survey will be shown the impact of technology at polytechnics in Croatia and in the discussion we will to explain why this is so because we assume that Web technology underutilized in higher education.

Keywords: Web 2.0 tools, higher education, e- science, teachers and students JEL classification: $\mathrm{O} 3$

\section{Introduction}

Web 2.0 is a trend in World Wide Web technology, based on possibility that users can involve in creation concepts of Web, they must be interactive with them. Web 2.0 is a phrase which was made up in O'Reilly Media in 2004. The best explanation of that term is that users are not audience anymore, passive receivers of information; they take part in creation, modification and dissemination. Interactive communication with users and computers is allowed, and users became active participants. Web 2.0 is oriented towards practical things. It is focused on creation of contents and services which will be useful users of the Internet. People must communicate and Web 2.0 made that easier. The biggest part in creation of Web 2.0 has innovative technology, such as blogs, link-blogs, wikis, podcasts, and RSS feeds. Well, what are these Web 2.0 tools and services? Howe (2006-2007, p.60) categorize four general types of processes within Web 2.0 applications that reflect these ways of interacting: for sharing user-contributed content ("You make it"); for evolving communitydeveloped tagging and organizational schemes (folksonomies); for large sets of user contributed content ("You name it"); for the development of content collections by the user community (crowd sourcing) ("You work on it"), and for finding not only objects but trends and overviews of contributions ("You find it").

And the other hand the properties of Web 2.0 tools are:

- Web as platform - users can use applications through Web browser

- Users have control of information on the same Web site they belong 
- Web design encourages users to conduce Web contents or applications during the search

- Aspects of social networking

- Advanced graphic interface in comparison with Web 1.0

- Openness, freedom and collective intelligence (Batinic; Pandur, 2009, pp 2-12) Nowadays, the main role of mentioned tools with their properties is to improve communication, interaction and cooperation between teachers and students. Method of the survey is poll of the students and teachers at polytechnics. We would like to identify potential of Web tools in higher education and how they contribute to the innovation of the teaching process.

\section{Web 2.0 in Higher Education}

In the last few years we have witnessed the development of an increasing number of modern Web applications which features interactive two-way communication and Web applications where users provide content development feedback which ultimately results in enriching and increasing the quality of content on the Web. Elearning 2.0 is the name of the next generation e-learning, which is based on Web 2.0 principles. This concept completely changes the approach to e-learning that we have known. Students are creating knowledge through interaction and exchange of experiences and information, instead of using content that was created by teachers. In addition, the e-learning process includes a series of Web technologies that are not primarily intended for studying. First of all it is about blogs, wiki systems, RSS and others which are previously mentioned that the e-learning is much more personalized, more social and more flexible process. (Anderson, 2007, pp 7)

\section{Web 2.0 Tools in e-education}

The process of e-learning in different ways can elevate a series of Web services which are integrated within the Web 2.0 concepts. Services will be divided into several categories: the exchange of media, communication, collaboration and creative learning, development of learning materials and learning management systems (LMS). (Cukusic; Jadrić, 2012)

Using multimedia in e-learning allows better absorption of the curriculum and principles, and therefore it is not surprising that it has developed a large number of Web services that enable sharing and storing all forms of media. Sharing photos is a Web service and is a very powerful resource because in one place can be access to large numbers of photographs that can be used for the purpose of making presentations, tasks, etc.

The main purpose of Web services for communication is the creation of social networks among students. Through the exchange of knowledge and experience they will acquire better knowledge. Some of the most significant is Myspace because it lets you create a social network for connecting people with similar interests and YackPack that enables students to ask questions, work on projects, collaborate in solving problems through audio conferences.

Collaboration and creative learning is a Web service which facilitates collaboration among a larger number of people who are physically remote and working on the same project and thus help creation of new knowledge. Here are some tools that support this service, including Bubbl.us - interactive tool to create mental maps that can be of great help in the work of a large number of students in a project or in collaboration around solving a problem. The generated maps can be sent to e-mail, printed out, saved and form images and put in a blog, website, etc. 
One of the tools is NoteMesh - free service that enables students to exchange notes and thus makes learning and taking courses easier. A tool where students can express their creativity through the booklet is LetterPop. All tools are subordinated to students for the nicer and easier education (Orehovacki et al., 2007, pp 145-155).

Also, the Web tools belonging and creating learning materials because teachers can organize and adapt to meet the needs of students and they present information in a variety of different ways, forms and media. Some of the services are as follows Slidestory that allows you to connect images and speech into one whole. In this way teachers can record their lectures and publish them on the Web, and then students can access these materials from any computer in the world and they can be used for learning, repetition, etc. Similar services are Slideshares. Among the other services in this category we will mention another Nanolearning service that provides fast, high-quality learning specific course content through a whole series of smaller parts. Each whole may contain audio in mp3 format and video in SWF format. Learning Management System (LMS) is platform that allows contact with the participants in one place, as well as access to information necessary for the completion of the course and provides the opportunity for each student evaluations. As all previously mentioned Web technologies are an integral part of the LMS, it is logical that the integration of Web 2.0 concepts and changes occurring within them. Changes that have occurred can be best observed through a description of the most popular learning management systems of the new generation. It should be mentioned Digitisation system that creates an e-portfolio with the aim of better connectivity, sharing and organization of resources. Everything that was created by using the LMS can be published in the form of interactive summaries, archives of performed work, the compilation of material for learning, collaborative materials, etc.

All these systems show that the Web 2.0 concept is integrated into the process of e-learning. The biggest changes that have occurred are held in the activities of students who are no longer passive recipients of information, but the creators of knowledge. The basic characteristics of the new era of e-learning are collaboration, connectivity, interaction and exchange of all forms of media and documents. The traditional LMS systems have evolved into a platform for creating social networks of learning in one place to access all Web services and the most appropriate way to enrich the process of e-learning. (Orehovacki et al., 2007, pp 145-155)

Thus the potential for the application of Web 2.0 tools and philosophy to lead to innovation in higher education clearly exists. And the students are ready for it. Without higher education institutions promoting it, students are making extensive use of Web 2.0 tools and processes to support their studies as well as for activities outside the range of higher education. (Collis; Moonen, 2008, pp. 96)

\section{Results of research}

The study described in this paper comes from research project which is implemented through data collected by survey. Survey was carried out in March of 2014. The preceding stage had collected data to determine the extent to which students and teachers at Croatian polytechnics are using Web 2.0 tools and why. A key finding was that, at the time data was collected, only a minority of the 500 students and 100 teachers surveyed were users of Web 2.0 tools. For example, 13\% of students surveyed had kept their own blog, $17 \%$ had read someone else blog, $50 \%$ had used data exchange systems, $32 \%$ had used Learning Management Systems, $22 \%$ had used collaboration tools. From teachers surveyed, $7 \%$ had kept their own blog, 16\% 
had red someone else blog, $47 \%$ had used data exchange systems, $51 \%$ had used Learning Management Systems, $11 \%$ had used collaboration tools.

Survey covered teachers of all Croatian polytechnics and students at Polytechnic of Pozega.

The trend of Web 2.0 has not bypassed Croatia. We conducted a small survey with teachers and students to see how well the Web tools are present in higher education. The survey approached the teachers and students in the social sciences. With survey we wanted to confirm thesis that the Web 2.0 tools ubiquitous in our lives, but they are still not used to considering how quickly develop as people are a bit sceptical about new things. From Web tools most used are communication tools such as Facebook and MySpace, as well as tools for sharing media of which is the most popular YouTube and Google Docs. Both, students and teachers, agreed with the above advantages of Web tools (group work, sending and transmission of the results, faster communication, ease of use, availability, timeliness, reduce of time and costs). Also we have listed the possible shortcomings and they were mostly neutral.

Figure 1

Use Web 2.0

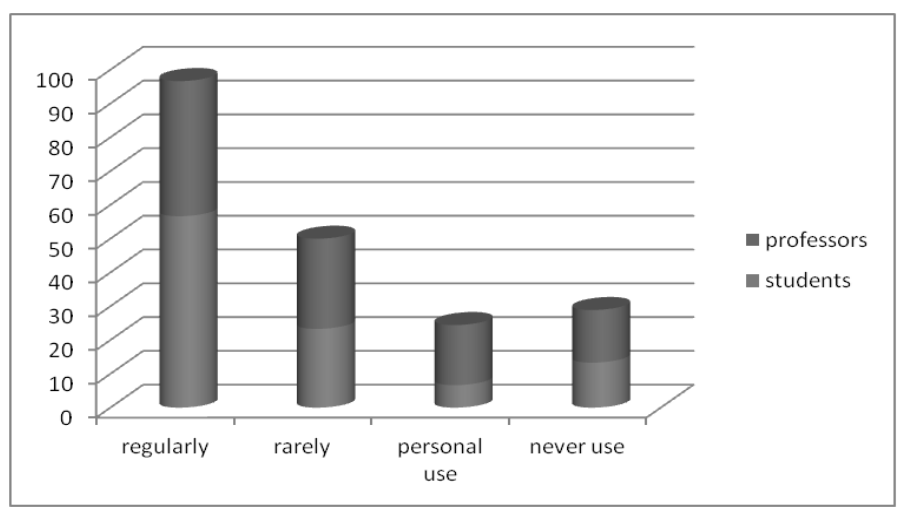

Source: Author's illustration

Teachers are using Moodle tool in Croatian learning management, and collaboration tools are considered unknown. And what is interesting, they are all considered to be the use of Web 2.0 tools to increase over the next five years and thus change the teaching that is currently taking place combining traditional and modern teaching. Everyone is somehow close with traditional teaching and it is difficult to separate from it.

The flash survey, which examined the expert study clearly shows that tools penetrate into teaching, but in a slower pace because we are quite sceptical about the changes. Also, we are aware that this will soon change and shift happens because the tools are ubiquitous and impossible to ignore.

Web 2.0 includes significant economic potential. On one side is the socialization element that allows users to socialize through the Internet and on the other side is financial reason that provides advertising space which means profit. Financial side is exploited by users who are studying habits of consumers through it and adapting marketing to the individuals. That kind of common interest is reason of success of the Web 2.0 concept. We are not talking just about the Internet and IT market, but also on a range of economic sectors and branches. Good example is already mentioned Google Docs \& Spreadsheets service that is just preparation for the total Google Office package. It will offer all the functionality of traditional office package. There will be possibility of writing and processing of text, tables, presentations and 
similar, but it will be free and available to everyone and from everywhere because, it will exist on your computer and on the Internet. Some examples of services and sites that are classified as Web 2.0 are: eBay, Wikipedia, Skype, Reddit, etc.

Figure 2

Results of survey

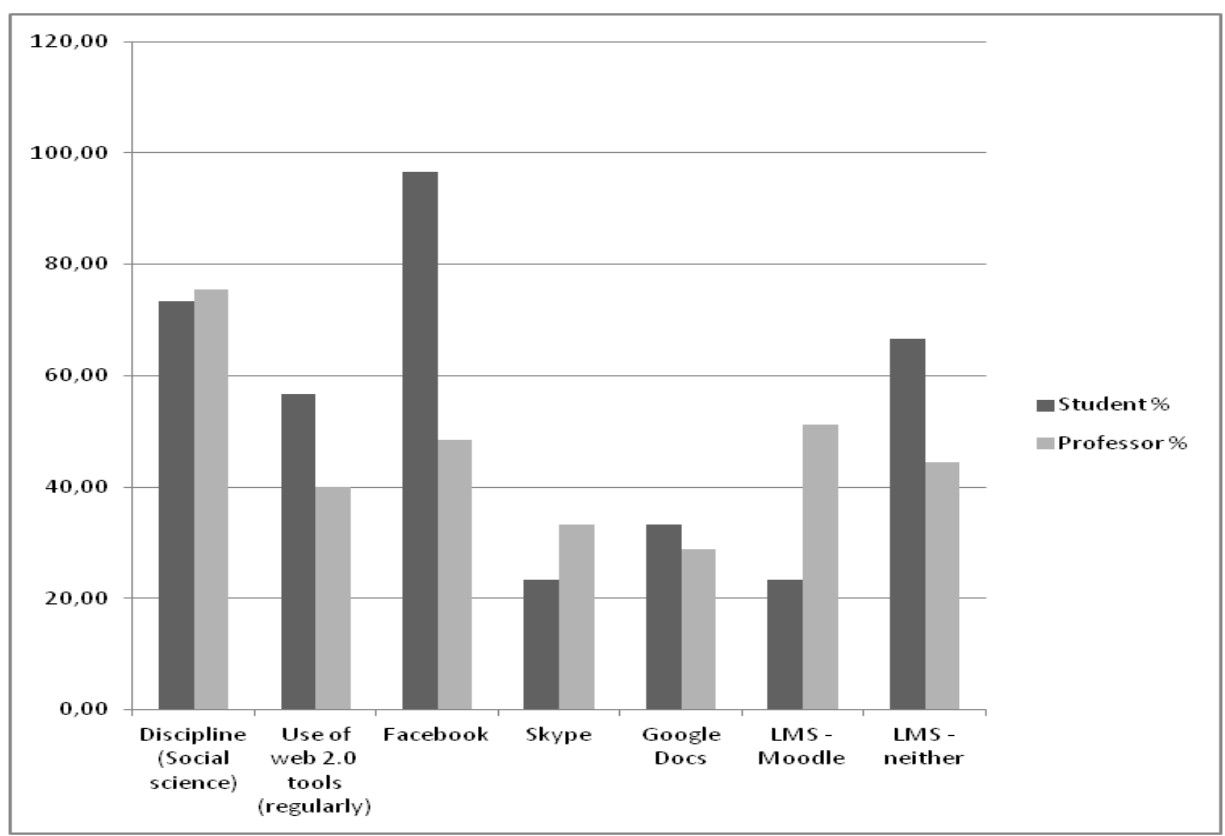

Source: Author's illustration

\section{Discussion}

This paper confirms the potential of Web 2.0 to support learning and learners. Yet the evidence is that learners do not always use Web 2.0 tools in straightforward educational ways, and their uses of Web 2.0 technologies remain more limited in scope than the rhetoric sometimes suggests. Web 2.0 tools and practices are not being drawn into education as vigorously as might be expected, despite the many examples of best practice that can be highlighted. Moving the Web 2.0 debate forward will mean going beyond the abstract, context-free discussion where the educational potential of Web 2.0 is seen as involving autonomous activities taking place totally in online environments. This approach suggests that 'education 2.0' will come about as Web 2.0 tools are appropriated by learners independently of formal educational systems. This points to the need to think carefully about the clash between learners' informal uses of Web 2.0 tools and the rather more formal aims and activities of teachers and educational institutions. Web 2.0 tools can have a profoundly challenging and disruptive influence in an educational setting. Wikis, blogs and mash-ups present specific challenges to existing terms of academic authorship, authority and integrity. While more radical educators may welcome these disruptive qualities, they may cause others to approach Web 2.0 with caution or discount the use of Web 2.0 tools altogether except when they reinforce existing practices and structures.

Given the undoubted educational potential of Web 2.0, we would argue that it is incumbent upon educationalists to seek ways to soften the gap between informal practices and formal procedures, and encourage and engineer more extensive, expansive, imaginative and empowering uses of Web 2.0 by learners and teachers. 
Schooling is likely to remain the dominant form of learning in society, at least in the short to medium term. We need to seek to reconcile schooling with the challenges of Web 2.0, and to explore opportunities for engineering re-schooling rather than deschooling. (Noss, 2012, pp 24-25)

\section{Conclusion}

Web 2.0 is still developing and will be subject to substantial changes as tools and applications evolve into Web 3.0 and beyond. It is likely that some of the clashes between formal structures of education provision and less formal technology practices will recede over time. As Annette Wang reminds us, the internet is still only in an 'adolescent' stage of development, and as a result is playful, over-emotional and profoundly informal. Yet many of the issues raised in this paper will remain relevant to the discussion of whatever Web technologies are overcome in the near future, when Facebook, YouTube and Wikipedia have been replaced and usurped by new tools and application

Discussion of Web 2.0 and learning needs to move beyond asking whether Web 2.0 applications 'work' in education or enhance learning. Instead, educational technologists need to consider how Web 2.0 can be shaped and designed along educational lines, and how education can be re-imagined in the light of new technologies. Educators should now be gravitating to work with technologists to shape the learning technologies of the near future. Learners require Web 2.0 technologies that are fit for purpose alongside pedagogies and practices that are too. Only then can the undoubted educational potentials of Web 2.0 be fully realised.

\section{References}

1. Anderson, P. (2007), "What is Web 2.0? Ideas, technologies and implications for education" JISC Technology and Standards Watch, Oxford: University of Oxford, pp. 711.

2. Batinic, N., Pandur, D. (2009), "Organization of the telecommunication net", Faculty of electrical engineering and computing, Zagreb, pp. 2-12, unpublished.

3. Collis, B., Moonen, J. (2008), "Web 2.0 tools and processes in higher education: quality perspectives", Educational Media International, Vol. 45, pp. 93-106.

4. Cukusic, M., Jadric, M. (2012), "E- learning: concept and use", Zagreb, Skolska knjiga.

5. Howe, J. (2006-2007), "Your web, your way", Time magazine, Vol. 168 No. 26, pp. 60-63.

6. Noss, R. (2012), "Education 2.0? Designing the web for teaching and learning", Engineering and Physical Sciences Research Council, London, Technology Enhanced Learning, pp. 24-25.

7. Orehovacki, T., Konecki, M. (2007), "Web 2.0 and e- learning evolution", Proceedings of the scientific and professional meeting "E-learning", Faculty of organization and informatics, Varaždin, pp. 145-155.

\section{About the authors}

Antonija Marinclin was born in Pozega. She works at Polytechnic in Pozega in Library as a Librarian. She has diploma for professor of history and for librarian from University of J. J. Strossmayer in Osijek, Faculty of humanities and social sciences. She is The President of the Commission for the publishing activities and also proofread material for college. She has written several papers and participated in international conferences. Author can be contacted at avalesic@vup.hr 
Ivana Mikic is an associate in Financial and Accounting Service at Polytechnic in Pozega, Pozega. She has diploma in economic sciences (financial management) from University of Josip Juraj Strossmayer in Osijek Faculty of Economics. She has European Business Competence*Licence (EBC*L) Level A and B, she is also Erasmus+ Administrator at Polytechnic in Pozega and Accountant of three Projects financed by EU. Ivana Mikic took part in Staff training mobility programmes, last year she spent a week at University of Lapland in Rovaniemi, Finland and in April of 2015 she participated 6th International Staff Week at University of Almeria in Almeria, Spain. She has written several papers and participated in international conferences. Author can be contacted at imikic@vup.hr

Marija Blazicevic has graduated Faculty of Kinesiology at the University of Zagreb in May 2011 . She works on Polytechnic in Pozega since July 2011. She was Teaching Assistant in the field of social sciences, field of kinesiology, sport kinesiology branch (College Physical Education I and II.) on social and agricultural department. In June 11 th, 2015 she was elected to the educational title of lecturer in the field of social sciences, field of kinesiology (College Physical Education I and II.) on social and agricultural department at the Polytechnic in Pozega. She has published two review papers and 4 professional papers and participated in international conferences, seminars and workshops. Marija Blazicevic participated in Staff training mobility programmes. Last year she spent a week at University of Lapland in Rovaniemi, Finland and in April of 2015, and she participated in 6th International Staff Week at University of Almeria in Almeria, Spain. Author can be contacted at mblazicevic@vup.hr 